Review Article

\title{
The COVID-19 Pandemic and Diet Change
}

\author{
Hong Chuan Loh ${ }^{1 *}$, Yin Kar Seah', Irene Looi ${ }^{1,2}$
}

\author{
Article History \\ ${ }^{1}$ Clinical Research Centre, Hospital Seberang Jaya, Ministry of Health \\ Received: 25 March 2021; \\ Malaysia, Seberang Jaya 13700, Penang, Malaysia; lohhongchuan@gmail.com \\ (HCL); seahyinkar@hotmail.com (YKS) \\ Received in Revised Form: \\ 20 May 2021; \\ ${ }^{2}$ Medical Department, Hospital Seberang Jaya, Ministry of Health Malaysia, \\ Seberang Jaya 13700, Penang, Malaysia; irenelooi@yahoo.com (IL) \\ Accepted: 25 May 2021; \\ *Corresponding author: Hong Chuan Loh, lohhongchuan@gmail.com (HCL) \\ Available Online: 1 June \\ 2021
}

\begin{abstract}
COVID-19 is now considered one of the world's greatest challenges. Even today, health experts and scientists are still seeking a conclusive answer regarding the source of this zoonotic disease. During the COVID-19 pandemic, plant-based diets became a preferred diet choice for many people. In this paper, we discussed the trend toward a plant-based diet across the globe and some of the reasons for the shift. We note that there was a rise in plant-based food sales and a simultaneous decline in animal-based meat sales. Sales of meat and seafood plummeted for many reasons, including distrust in meat due to fear of virus contamination, price increases, and ethical reasons. Marketing strategies used by meat-alternative companies may have also played a role. While there has been an ongoing trend toward plant-based diets in recent years, that trend seemed to accelerate during the pandemic with more available vegan venues and places with vegan options. Another reason that some people may have started exploring plant-based eating during the pandemic is because of the belief that such healthy eating will boost immunity or provide some other health-related benefit. Plant-based diets are also more cost-effective than diets containing meat, fish, and dairy. We conclude that significant changes need to be made regarding the use of wild animals and livestock in order to prevent future pandemics of zoonotic origin. As the world's population grows, zoonoses may occur with greater frequency. Encouraging the adoption of healthy plant-based diets around the world with a simultaneous reduction in the use of animals as a food source is necessary and vital steps to prevent future pandemics due to zoonotic disease.
\end{abstract}

Keywords: COVID-19, pandemic, plant-based diet, vegan, meat 


\section{Introduction}

Coronavirus disease-2019 (COVID-19) was declared a pandemic by the World Health Organization (WHO) on March 11, 2020 $0^{[1]}$. As of $17^{\text {th }}$ May 2021, over 160 million people are infected with the virus and more than three million deaths worldwide. Unfortunately, these numbers are still on the rise.

When this disease first broke out in Wuhan, China, it was initially identified as pneumonia, cause unknown ${ }^{[2-5]}$. In only a few months, it spread to the rest of the world. Many of the original cases of COVID-19 seemed to have connected to the Huanan seafood wholesale market. It was subsequently determined that COVID-19 is caused by the virus Severe Acute Respiratory Syndrome Coronavirus-2 (SARS-CoV-2). SARS-CoV-2, from the family Coronaviridae, and is a $96 \%$ identical match at the whole-genome level to a bat coronavirus $^{[6-8]}$. Although bats are a probable reservoir host for the virus, scientists had suggested that Malayan pangolins (Manis javanica) may have served as a possible intermediate host for SARS-CoV-2 before it was transmitted to humans ${ }^{[9]}$. The strain of the disease that affected humans evolved to become transmissible by human-to-human contact $^{[10]}$. There was also some debate about whether swine may have been the intermediate host for the virus, either instead of or in addition to the pangolins ${ }^{[11]}$. As numerous zoonotic outbreaks emerged from livestock farms in the past, it is possible that there was a bat-swinehuman relationship with the spread of COVID-19 due to the extensive swine factory farms in Wuhan, China ${ }^{[11]}$. There was also some speculation about a relationship between the spread of COVID-19 and the location of swine factory farms in Santa Catarina, Brazil ${ }^{[11]}$. The world's current food production and consumption paradigm has created the conditions for repeated zoonosis and is the root of the problem ${ }^{[12]}$.

According to the World Health Organization, zoonotic disease, or zoonosis, is an infectious disease that has jumped from animals to humans. Zoonotic pathogens may be bacterial, viral, parasitic, or may involve unconventional agents and can spread to humans through direct contact or food, water, or the environment ${ }^{[13]}$. Outbreaks of zoonotic disease in humans have occurred many times over thousands of years of human evolution, but the rate of zoonotic transmission has been rising over time ${ }^{[14,15]}$. For example, zoonotic pathogens such as the Severe Acute Respiratory Syndrome coronavirus and the Middle East respiratory syndrome coronavirus both caused pandemics in the past two decades ${ }^{[16]}$. In order to prevent or at least limit future outbreaks of zoonotic disease, it is crucial to identify and address the causes of the zoonotic links (in both wild animals and livestock) and the "spillover events" that give rise to the transmission of novel infectious viruses ${ }^{[17]}$. The sale of wild animals at the seafood market in Wuhan appears to be the most likely source of 
COVID-19 ${ }^{[18]}$. Therefore, experts urged that authorities put in place a permanent global ban on wildlife consumption and the operation of wildlife markets. These steps are generally regarded as critical in preventing future pandemics ${ }^{[19]}$. There were also numerous mammalian and non-aquatic species, such as rabbits and birds, that were available at that market for purchase before the outbreak ${ }^{[20]}$. These animals could also serve as hosts for different species and strains of coronaviruses. The shedding of viral particles in the faeces of these animals may play a role in infectious spread, including in cross-species transmissions ${ }^{[21]}$.

In April 2020, the acting Head of Biodiversity at the United Nations said that countries could avoid pandemics by eliminating wildlife markets that trade live and dead wild animals for human consumption ${ }^{[22]}$. Wildlife markets and illicit trade in wild animals have been identified by public health authorities in the United States (US) and around the world as conduits for the transmission of diseases. The transfer of diseases from animals to humans can happen by human consumption of live or dead animals or even by the close proximity of humans to live or dead animals. In addition, livestock animals can be infected by contact with wild animals and wet markets provide a particularly conducive environment for this kind of spread. Strict laws against both the sale of live animals and the exotic meats trade should be enforced ${ }^{[23]}$. Because of the COVID-19 outbreak, the Chinese government has now imposed a national ban on the use of wild animals for food ${ }^{[24]}$. It is at least a step in the right direction.

The current zoonotic pandemic has caused health professionals around the world to address issues such as wet markets and livestock, and some of these comments have been highlighted in the media. This level of attention may cause the eating pattern of many to change as a result of the COVID-19 crisis. This paper addresses the change in food choice by many people, the reasons for such change, and the lessons we could learn for the future as a result of the COVID-19 pandemic.

\section{Global Diet Trends}

Figure 1 is a graphical abstract to illustrate the main findings of this review. 


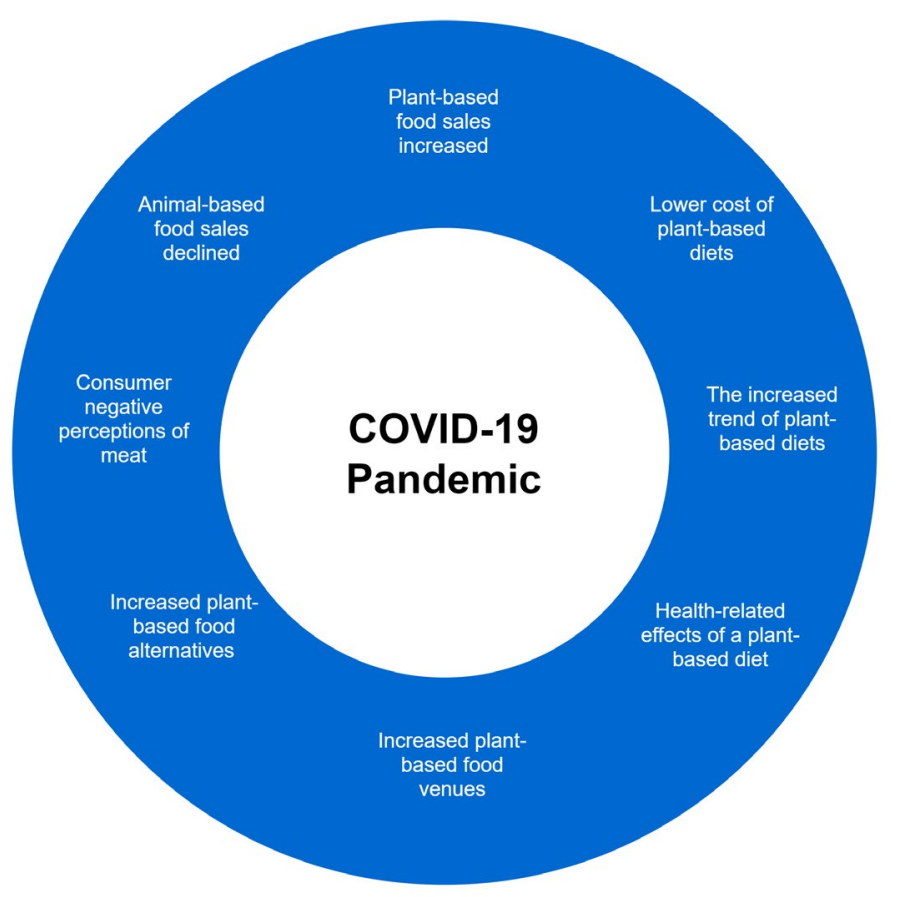

Figure 1. Summary of the review (the COVID-19 pandemic and diet change).

\subsection{Plant-based Food Sales And Animal-Based Food Sales}

During the COVID-19 pandemic, there was an interesting shift in diet among many as plant-based food consumption, including meat alternatives, increased significantly. In this paper, we use the terms "vegan" and "plant-based" interchangeably but recognize that veganism relates to the rights of non-human species, whereas plant-based refers to only dietary choice. The US retail sales of plant-based foods greatly outpaced overall food sales suggesting that more customers turned to plant-based foods during the pandemic. March 2020 was the peak of food buying during the pandemic, and it is noteworthy that plant-based food sales grew by $90 \%$ compared to March 2019 . When broken down by segment, vegan meat sales rose by $148 \%$ and continued to rise by $61 \%$ in the following four weeks, reflecting a growth rate two times that of animal-based meat ${ }^{[25]}$.

While plant-based meat sales continued to soar, animal-based meat sales continued to decline. The United Kingdom (UK) Department for Environment, Food and Rural Affairs compared animal slaughter data from October 2020 to October 2019 and found a decrease of $7.3 \%$ in prime cattle, $4.9 \%$ in clean sheep, and $2.1 \%$ in clean pig slaughtering ${ }^{[26]}$. According to a report from the Food and Agriculture Organization of the United Nations, it is expected that the numbers from 2020, when finally tallied, will show that meat consumption per capita decreased by nearly $3 \%$ globally and that this reduced consumption was the biggest annual decline since $2000^{[27]}$. The COVID-19 pandemic also negatively affected the meat products market in Southeast Asia. Due to the major hit to the livestock industry, revenue losses, and 
supply shortages, it was estimated that there was a lower growth rate during the outbreak. Meat producers in Southeast Asia faced drastically reduced meat consumption as well as a scarcity of raw materials and were severely hampered by these factors ${ }^{[28]}$.

Seafood sales also plummeted during the pandemic. Fishing communities and ports were seen as possible hubs for transmission of COVID-19 infection because of the migratory nature of fishermen and the frequency of international visitors ${ }^{[29]}$. Many fisheries experienced partial or complete shutdown resulting in a reduction of fishing activities globally. Furthermore, there was a drastic reduction in demand for seafood, restriction to access cold storage, and cessation of shipping and air cargo ${ }^{[30]}$. Activity on the Fish Exchange in Portland, Maine, US, declined from 60,000 to about 20,000 pounds per week during the pandemic ${ }^{[31]}$. The closure of many restaurants in the US significantly decreased demand and the nation's fisheries across geography, species, gear types, and management reported sales nosedives of up to $95 \%{ }^{[32]}$.

\subsection{COVID-19 and Consumer Perceptions of Meat}

A particularly significant concern with the COVID-19 outbreak is the high infection rate among workers at slaughterhouses and meat processing plants. The environment in such facilities is conducive for zoonotic spread. There are structural and operational practices that hinder the practice of personal safety protection and the proper cleaning and disinfection of worksites. The facilities also have lower temperatures and extreme relative humidity, large quantities of droplets and aerosols, and use many stainless-steel surfaces that retain live viruses longer than cloth or paper surfaces. These conditions, along with the sociocultural and economic challenges facing the workers, facilitate the transmission of SARS-CoV$2^{[33,34]}$. It is therefore not surprising that a series of SARS-CoV-2 outbreaks that occurred between March and June 2020 in meat factories led to plant closures, especially in Europe and North America, including some in Germany, France, Spain, the UK, the US, and Canada $^{[35,36]}$. Gütersloh and Warendorf in the Western German state of North RhineWestphalia, with a total of 640,000 residents, were returned to lockdown conditions after more than 1,400 employees at a meat-packing plant tested positive for COVID-19 ${ }^{[37]}$. Meat processing factories in Anglesey, Merthyr Tydfil, Wrexham, and Kirklees in the UK also became hot spots with over 450 COVID-19 cases $^{[38]}$. Among 115 meat or poultry processing facilities in 19 states in the US, 4,913 employees were diagnosed with COVID-19 and 20 deaths related to COVID-19 were reported ${ }^{[34]}$. Specifically, the largest reported cluster was 1,550 cases linked to a single meat-packing plant in Alberta, Canada ${ }^{[39]}$.

With meat processing plant closures due to COVID-19 outbreaks, consumers may have had concerns about meat shortages and meat safety (due to its possible contamination 
with the virus), causing higher demand for plant-based alternatives. It is also possible that consumers may have been concerned about meat prices since the decline in the availability of meat could result in price increases. A higher cost for meat would further reduce the demand for meat. There is also the possibility that consumers may have deliberately protested against the meat to stand in solidarity with workers from slaughterhouses and meat processing plants ${ }^{[40]}$. A study conducted in China during the pandemic showed an increased demand for a plant-based diet. Apart from dieting to lose weight, the study participants considered a plant-based diet safer for consumption, possibly implying distrust in meat ${ }^{[41]}$. A study by Forsa on the eating habits of Germans between 2015 and 2020 commissioned by the Federal Minister of Food, Julia Klöckner, showed that the country's daily meat intake as a percentage of the average German meal declined among the respondents from $34 \%$ to $26 \%{ }^{[42]}$.

\subsection{Plant-based Food Alternatives and Venues}

As meat and seafood supply chains face disruption during the pandemic, plant-based companies that offer meat alternatives like "Beyond Meat" and "Impossible Foods" are seizing the chance to secure new customers with more competitive marketing strategies ${ }^{[43]}$. According to Grubhub's "Year in Food" trend report in which the delivery platform analysed 30 million orders, plant-based meat alternatives spiked in popularity by $463 \%$ in 2020 . Across the US, New York, California, Oregon, Massachusetts, and Illinois took the top five spots. In addition, delivery platform DoorDash, with a newly released "DoorDash Deep Dish" report, also showed an increase in plant-based alternatives, specifically $433 \%$ in the six-month period from January 2020 to the end of June $2020^{[44]}$.

Other research by an online restaurant resource (the HappyCow platform) focused on how restaurants have been affected by COVID-19. It found that since the onset of COVID19, there were 517 newly opened vegan restaurants while 413 were closed, with a total of 104 more vegan restaurants available now worldwide ${ }^{[45]}$. As the results only represent purely vegan venues, the number of restaurants that are "vegan-friendly" or that have plant-based options available may have increased. Even fast-food restaurant chains are offering more plant-based options. The largest chain in the world, Subway, launched a Meatless Meatball Marinara Sub sandwich in all of its UK stores in early 2020 with a successful sell-out of the product. It won Best Vegan Sandwich at the 2020 Vegan Food Awards hosted by People for the Ethical Treatment of Animals ${ }^{[46]}$. Starbucks, the third-largest chain store, also added more plant-based items to its menu worldwide, such as Impossible Rendang Pie in Singapore, Beyond Meat dishes, and Oatly milk substitute in China, as well as many others in various locations $^{[47]}$. 


\subsection{A Plant-Based Diet and Its Health-Related Effects}

The surge in demand for a plant-based diet could also be due to greater awareness of the benefits of leading a healthier lifestyle and the belief that it could result in stronger immunity. According to a current pan-India serosurvey conducted by the Council of Scientific and Industrial Research in its almost 40 institutes, vegetarians were found to have lower COVID-19 seropositivity, suggesting that they might be at a lower risk of coronavirus infection ${ }^{[48]}$. With a strong impact on host homeostasis and immunostasis, it is known that the gut microbiota that reside in the gastrointestinal tract provide their host with important health benefits ${ }^{[49]}$. Hong Kong researchers have identified three significant findings in patients with COVID-19: a) the composition of the gut microbiota is consistent with disease severity and magnitude of plasma concentrations of several inflammatory cytokines, chemokines, and blood markers of tissue damage; b) gut bacteria such as Faecalibacterium prausnitzii, Eubacterium rectale, and many species of bifidobacteria, with known immunomodulatory capacity, have been depleted; c) the dysbiotic gut microbiota composition remains after virus clearance ${ }^{[50]}$. A recent study showed favourable association between healthy plant-based food consumption and "good" microbes in the body ${ }^{[51]}$. This was due to the fact that a plant-based diet replenishes the host intestinal microbiota with beneficial microbes while maintaining a state of symbiosis with balanced microflora within the host that results in multiple health benefits, including improved immunity ${ }^{[52]}$. For instance, fibre, which is widely available in plants, has been found to consistently increase lactic acid bacteria, such as Ruminococcus, E. rectale, and Roseburia, and limit the growth of the Clostridium and Enterococcus species. Polyphenols, also found exclusively in plants, tend to increase Bifidobacterium and Lactobacillus ${ }^{[53]}$.

Many of the risk factors reported to date that are associated with COVID-19 infection and mortality relate to nutritional status and specific essential nutrients. A balanced diet with an abundance of vegetables, fruits, whole grains, and nuts is associated with many substantial health benefits owing to the high amounts of fibre, polyphenols, vitamins, unsaturated fats, and minerals ${ }^{[54]}$. There was level I and II evidence that supports the use of vitamins B, C, and $\mathrm{D}$ in the treatment of coronavirus-like respiratory diseases, acute respiratory distress syndrome, and sepsis ${ }^{[55,56]}$. Vitamin $\mathrm{D}$, in particular, has been found to play a role in reducing the risk of COVID-19 infections and deaths ${ }^{[57]}$. While many food sources only contain low amounts of vitamin D naturally, certain plant sources, such as algae, fungi, and yeasts, contain abundant amounts of vitamin $\mathrm{D}$ as well as provitamin $\mathrm{D}^{[58]}$. As mushrooms, fungi, and seaweed are commonly found in Asian cuisine, predominantly among the Chinese, Japanese, and Korean communities, it is interesting to note that some Asian countries have managed to keep the outbreak of COVID-19 under control and have experienced lower 
mortality rates. This observation suggests further study on immunonutrition to determine any links that may exist. Previous research also demonstrated that many naturally occurring compounds with anti-coronavirus infection properties could be found in common fruits. A recent study regarding tannic acid, which is abundant in fruits like grapes, berries, and apples, demonstrated high potential as part of developing anti-COVID-19 therapeutics. Tannic acid acts as a potent dual inhibitor of two independent enzymes (the main viral protease and the cellular TMPRSS2 protease), resulting in some degree of SARS-CoV-2 infection suppression $^{[59]}$.

\subsection{The Trend and Cost of Plant-Based Diets}

A study using Google Trends data was carried out to examine the popularity of "vegan" search terms around the world in a variety of languages. It showed that the popularity of veganism was at an all-time high in the midst of the pandemic in 2020 and surpassed the previous all-time high reported in 2019. Among all the countries in the world, the UK, Australia, and Israel hold the top three spots for being most inquisitive about plant-based diets. Moreover, the vegan trend is now twice as popular as it was five years ago ${ }^{[60]}$. The vegan diet has also received the highest quality score for any diet as represented by the Healthy Eating Index 2010 and the Mediterranean Diet Score in a study that included 1,475 participants ${ }^{[61]}$. In addition, a recent recommendation by the EAT-Lancet Commission on healthy diets from sustainable food systems supports a $50 \%$ or more reduction in the global consumption of unhealthy foods, including meat, by 2050 in order to meet global nutritional needs while preserving local and global ecosystems ${ }^{[62]}$. With greater opportunity to prepare meals at home and have more free time to learn about a healthier diet during home confinement compared to pre-quarantine days, there is probably a greater likelihood that people will choose plant-based food.

A recent study showed that a plant-based meal prepared at home costs $40 \%$ less than meat or fish meals ( $£ 1.77$ per person for a meat/fish meal versus $£ 1.06$ per person for a plantbased meal), and it takes one-third less time to prepare. These calculations are based on weekly meal diaries that were captured online from around 11,000 people in Britain ${ }^{[63]}$. The COVID-19 pandemic has affected 55 million domestic workers worldwide, many of whom were in fear of or actually experienced reduced working hours, lost income, and even loss of employment altogether ${ }^{[64]}$. The lower cost of plant foods versus meat or fish could also have contributed to the increase in the number of people adopting a plant-based diet during the crisis.

COVID-19 may have added momentum to an already rapidly growing trend toward the consumption of a healthier plant-based diet. As a result of increased awareness about the 
detrimental effects of meat consumption on the environment and human health, and for ethical reasons relating to animal rights, plant-based diets are increasingly popular and are often promoted by celebrities and athletes. The Acumen Research and Consulting report projects that the global vegan food market will reach around US\$24.3 billion by 2026 and will grow at a noteworthy compound annual growth rate of around $9.1 \%$ throughout the forecast period from 2019 to $2026^{[65]}$.

\section{Lessons to Learn From the COVID-19 Pandemic}

Acknowledging the need for multidisciplinary collaboration to resolve health threats at the human-animal-ecosystem interface, the WHO, the Food and Agriculture Organization, and the World Organisation for Animal Health formalized a partnership in 2010 and identified three priority areas of collaborative work, two of which relate to zoonotic diseases $^{[66]}$. In addition to giving rise to global infectious disease threats, an analysis performed by the World Bank estimated that the economic losses from six major outbreaks of zoonoses were at least US\$80 billion between 1997 and 2009 ${ }^{[67]}$. In view of the deleterious effect of zoonotic disease, all countries should focus on ways to prevent future pandemics. Since the COVID-19 pandemic began, consumers have become better informed about the latest health-related information. Consumers should demand greater transparency about how their food is produced and be able to base their dietary choices on options that result in less burden to the planet and less opportunity for zoonotic diseases to arise. This would include adopting a healthy plant-based diet, banning all wildlife trade at wet markets, or enforcing stricter regulations, and prohibiting most human activities that involve close contact with wild animals, such as sport hunting. These steps would help to minimize the risk of human exposure to novel viral pathogens, improve food security, and reduce the effect of food production on the environment. The beneficial changes in diet that we observed during the pandemic may not be sustained if they are not entrenched into the daily habits of consumers. Established and well-regarded government agencies, such as the US Food and Drug Administration could play an important role in encouraging and incentivizing restaurants, schools, and hospitals to offer plant-based food options, engage on social media to promote a healthy vegan lifestyle, and provide plant-based nutritional guidance to all health professionals.

\section{Conclusion}

The COVID-19 pandemic has presented an exceptional situation in which many people around the world, aware of the causes of zoonoses and the health benefits of eating a plant-based diet, have changed their eating patterns. Apart from the numerous beneficial health, environmental, economic, and ethical effects of a plant-based diet, the prospect of 
lessening the risk of future pandemics is perhaps the most important to many people. Multidisciplinary health experts and authorities across the globe should come together to produce and implement common sense and data-driven solutions. The emphasis should be on eliminating, or at least reducing, the use of wild animals and livestock for any purpose, particularly as a source of food, in order to mitigate future pandemics due to zoonotic disease.

Author Contributions: HCL and YKS drafted the manuscript. HCL and IL provided review and editing for this manuscript. HCL, YKS and IL conceptualized this review writing project.

Funding: No external funding was provided for this research.

Acknowledgments: We would like to thank the Director-General of Health Malaysia for his permission to publish this article.

Conflicts of Interest: The authors declare no conflict of interest.

\section{References}

1. Mitra P, Misra S, and Sharma P, COVID-19 pandemic in India: What lies ahead. Indian J Clin Biochem 2020: 1-3.

2. Loo KY, Letchumanan V, Ser HL, et al., COVID-19: Insights into potential vaccines. Microorganisms 2021; 9(3).

3. Tan LT-H, Letchumanan V, Ser H-L, et al., PMMB COVID-19 Bulletin: United Kingdom (22nd April 2020). Prog Microbes Mol Biol 2020; 3(1).

4. Johnson D, Ren SEC, Johnson HD, et al., COVID-19: Are Malaysians embracing or suffering the new normality? Prog Microbes Mol Biol 2020; 3(1).

5. Letchumanan V, Ab Mutalib N-S, Goh B-H, et al., Novel coronavirus 2019-nCoV: Could this virus become a possible global pandemic. Prog Microbes Mol Biol 2020; 3(1).

6. Zhou P, Yang XL, Wang XG, et al., A pneumonia outbreak associated with a new coronavirus of probable bat origin. Nature 2020; 579(7798): 270-273.

7. Ng SL, Ong YS, Khaw KY, et al., Focused review: potential rare and atypical symptoms as indicator for targeted COVID-19 screening. Medicina (Kaunas) 2021; 57(2).

8. Ser H-L, Tan LT-H, Law JW-F, et al., Genomic analysis of severe acute respiratory syndrome coronavirus 2 (SARS-CoV-2) strains isolated in Malaysia. Prog Microbes Mol Biol 2020; 3(1).

9. Lam TT, Jia N, Zhang YW, et al., Identifying SARS-CoV-2-related coronaviruses in Malayan pangolins. Nature 2020; 583(7815): 282-285.

10. Chan JF, Yuan S, Kok KH, et al., A familial cluster of pneumonia associated with the 2019 novel coronavirus indicating person-to-person transmission: a study of a family cluster. Lancet 2020; 395(10223): 514-523.

11. Fiebrig I, Bombardi LM, and Pablo N. Hypothesising on the emergence of SARS-CoV-2 through bats: its relation to intensive pig-factory farming and the agro-industrial complex (discussion paper). 2020.

Available

at:

https://www.researchgate.net/publication/341525356_Hypothesising_on_the_emergence_of_SARS-

CoV-2_through_bats_Its_relation_to_intensive_pig-factory_farming_and_the_agro-

industrial_complex [Accessed on 5 Jan 2021]. 
12. Kumar R, Valuing variability: Agriculture, ecology and COVID-19. Society and Culture in South Asia. 2021: SAGE Publications India. 2393861720975222.

13. World Health Organization. Zoonoses. 2020. Available at: https://www.who.int/news-room/factsheets/detail/zoonoses [Accessed on 5 Jan 2021].

14. Fooks AR and Jackson AC, Rabies: scientific basis of the disease and its management. 3rd ed. 2013: Academic Press.

15. Jones KE, Patel NG, Levy MA, et al., Global trends in emerging infectious diseases. Nature 2008; 451(7181): 990-993.

16. Guarner J, Three emerging coronaviruses in two decades. Am J Clin Pathol 2020; 153(4): 420-421.

17. Halabowski D and Rzymski P, Taking a lesson from the COVID-19 pandemic: Preventing the future outbreaks of viral zoonoses through a multi-faceted approach. Sci Total Environ 2021; 757: 143723.

18. Lu R, Zhao X, Li J, et al., Genomic characterisation and epidemiology of 2019 novel coronavirus: implications for virus origins and receptor binding. Lancet 2020; 395(10224): 565-574.

19. Weston $\mathrm{P}$ and Standaert M. Make ban on Chinese wildlife markets permanent, says environment expert. 2020. Available at: https://www.theguardian.com/environment/2020/jan/30/makecoronavirus-ban-on-chinese-wildlife-markets-permanent-says-environment-expert-aoe [Accessed on 17 May 2021].

20. Cohen J, Mining coronavirus genomes for clues to the outbreak's origins. Sciencemag 2020; 31.

21. Wartecki A and Rzymski $\mathrm{P}$, On the coronaviruses and their associations with the aquatic environment and wastewater. J Water 2020; 12(6): 1598.

22. Greenfield P. Ban wildlife markets to avert pandemics, says UN biodiversity chief. 2020. Available at: $\quad$ https://www.theguardian.com/world/2020/apr/06/ban-live-animal-markets-pandemics-unbiodiversity-chief-age-of-extinction [Accessed on 5 Jan 2021].

23. Aguirre AA, Catherina R, Frye H, et al., Illicit wildlife trade, wet markets, and COVID-19: Preventing future pandemics. World Med Health Policy 2020; 12: 256-265.

24. Maron DF. Wet markets' likely launched the coronavirus. Here's what you need to know. 2020. Available at: https://www.nationalgeographic.com/animals/2020/04/coronavirus-linked-to-chinesewet-markets/ [Accessed on 5 Jan 2021].

25. SPINSscan. PBFA retail sales data showing performance of plant-based foods during pandemic makes headlines. 2020. Available at: https://www.spins.com/new-data-shows-plant-based-food-outpacingtotal-food-sales-during-covid-19/ [Accessed on 5 Jan 2021].

26. Department for Environment Food and Rural Affairs. United Kingdom slaughter statistics - October 2020. National Statistics 2020. Available at: https://assets.publishing.service.gov.uk/ [Accessed on 5 Jan 2021].

27. Food and Agriculture Organization of the United Nations. Biannual report on global food markets. Food outlook 2020. Available at: http://www.fao.org/documents/card/en/c/cb1993en/ [Accessed on 5 Jan 2021].

28. Research Dive. Southeast Asia meat product market expected to surpass $\$ 117,259.2$ million by 2026 - Exclusive report $[176$ Pages $]$ by Research Dive. 2020. Available at: https://www.globenewswire.com/en/news-release/2020/10/19/2110311/0/en/Southeast-Asia-MeatProduct-Market-Expected-To-Surpass-117-259-2-Million-by-2026-Exclusive-Report-176-Pages-byResearch-Dive.html [Accessed on 17 May 2021]. 
29. FAO, How is COVID-19 affecting the fisheries and aquaculture food systems. 2020, Rome: FAO.

30. Orlowski A. Small-scale fishermen suffering significantly from COVID-19 pandemic. 2020. Available at: https://www.seafoodsource.com/news/supply-trade/small-scale-fishermen-suffering-significantlyfrom-covid-19-pandemic [Accessed on 5 Jan 2021].

31. Federal Emergency Management Agency. Region I: COVID-19 long-term recovery task force. 2020. Available at: https://agriculture.vermont.gov/document/region-i-covid-19-long-term-recovery-taskforce-funding-opportunities [Accessed on 5 Jan 2021].

32. Reiley L. Commercial fishing industry in free fall as restaurants close, consumers hunker down and vessels tie up. 2020. Available at: https://www.washingtonpost.com/business/2020/04/08/commercialfishing-coronavirus/ [Accessed on 5 Jan 2021].

33. Durand-Moreau Q, Adisesh A, Mackenzie G, et al., COVID-19 in meat and poultry facilities: A rapid review and lay media analysis. The Centre for Evidence-Based Medicine 2020.

34. Dyal JW, Grant MP, Broadwater K, et al., COVID-19 among workers in meat and poultry processing facilities - 19 states, April 2020. MMWR Morb Mortal Wkly Rep 2020; 69(18).

35. Donaldson AI, Aerosols in meat plants as possible cause of Covid-19 spread. Vet Rec 2020; 187(1): $34-35$.

36. Ser H-L, Letchumanan V, Law JW-F, et al., PMMB COVID-19 Bulletin: Spain (18th April 2020). Prog Microbes Mol Biol 2020; 3(1).

37. Ešegović D. HNU Working Paper - A pandemic as the starting point of a corporate crisis using the example of tönnies. Hochschule für angewandte Wissenschaften Neu-Ulm 2020. Available at: https://publications.hs-neu-ulm.de/1838/1/Esegovic_WP_43_Pandemic-1 [Accessed on 5 Jan 2021].

38. Halliday J. Over 450 cases of COVID-19 reported at food factories in England and Wales. 2020. Available at: https://www.theguardian.com/uk-news/2020/jun/25/over-450-covid-19-cases-reportedat-food-factories-in-england-and-wales [Accessed on 5 Jan 2021].

39. EFFAT. Covid-19 outbreaks in slaughterhouses and meat processing plants. European Federation of Food, Agriculture and Tourism Trade Unions Report 2020. Available at: https://effat.org/wpcontent/uploads/2020/09/Covid-19-outbreaks-in-slaughterhouses-and-meat-processing-plants-Stateof-affairs-and-demands-for-action-at-EU-level-07.09.2020 [Accessed on 5 Jan 2021].

40. Attwood S and Hajat C, How will the COVID-19 pandemic shape the future of meat consumption? Public Health Nutr 2020; 23(17): 3116-3120.

41. Yaran Y. Shift towards vegan in China during COVID-19: An online behavioral survey study. In 2020 2nd International Conference on Economic Management and Cultural Industry (ICEMCI2020). 2020. Atlantis Press.

42. Forsa. Ernährungsreport 2019/2020. Ergebnisse einer repräsentativen Bevölkerungsbefragung 2020. Available at: https://www.bmel.de/SharedDocs/Downloads/DE/_Ernaehrung/forsaernaehrungsreport-2020-tabellen [Accessed on 5 Jan 2021].

43. Andria C. As meat supply chains face disruption, plant-based players like beyond meat see an opportunity. Forbes 2020. Available at: https://www.forbes.com/sites/andriacheng/2020/05/05/ [Accessed on 5 Jan 2021].

44. Anna S. Popularity of meat alternatives on grubhub spikes by 463 percent in 2020. 2020. Available at: https://vegnews.com/2020/12/popularity-of-meat-alternatives-on-grubhub-spikes-by-463-percent-in2020 [Accessed on 5 Jan 2021]. 
45. Spector K. 104 more vegan venues now on HappyCow since the start of COVID-19. 2020. Available at: https://vegconomist.com/market-and-trends/104-more-vegan-venues-now-on-happycow-sincethe-start-of-covid-19/ [Accessed on 5 Jan 2021].

46. Chiorando M. Subway U.K expands vegan options after sell-out success of Meatless Marinara. Plant Based News 2020. Available at: https://plantbasednews.org/lifestyle/vegan-subway-more-options/ [Accessed on 5 Jan 2021].

47. Starbucks stories \& news. Plant-based menu innovation at Starbucks. 2020. Available at: https://stories.starbucks.com/stories/2020/plant-based-menu-innovation-at-starbucks/ [Accessed on 5 Jan 2021].

48. Mumbai PA. Smokers, vegetarians at lower risk of contracting Covid-19: Study. 2021. Available at: https://www.thehindubusinessline.com/news/national/smokers-vegetarians-at-lower-risk-ofcontracting-covid-19-study/article33598138.ece\# [Accessed on 20 Jan 2021].

49. Lazar V, Ditu LM, Pircalabioru GG, et al., Aspects of gut microbiota and immune system interactions in infectious diseases, immunopathology, and cancer. Front Immunol 2018; 9(1830): 1830.

50. Yeoh YK, Zuo T, Lui GC, et al., Gut microbiota composition reflects disease severity and dysfunctional immune responses in patients with COVID-19. Gut 2021; 70(4): 698-706.

51. Asnicar F, Berry SE, Valdes AM, et al., Microbiome connections with host metabolism and habitual diet from 1,098 deeply phenotyped individuals. Nat Med 2021; 27(2): 321-332.

52. Rishi P, Thakur K, Vij S, et al., Diet, gut microbiota and COVID-19. Indian J Microbiol 2020: 1-10.

53. Tomova A, Bukovsky I, Rembert E, et al., The effects of vegetarian and vegan diets on gut microbiota. Front Nutr 2019; 6: 47.

54. Craig WJ, Health effects of vegan diets. Am J Clin Nutr 2009; 89(5): 1627S-1633S.

55. Jovic TH, Ali SR, Ibrahim N, et al., Could vitamins help in the fight against COVID-19? Nutrients 2020; 12(9): 2550.

56. Hiedra R, Lo KB, Elbashabsheh M, et al., The use of IV vitamin C for patients with COVID-19: a case series. Expert Rev Anti Infect Ther 2020; 18(12): 1259-1261.

57. Grant WB, Lahore H, McDonnell SL, et al., Evidence that vitamin D supplementation could reduce risk of Influenza and COVID-19 infections and deaths. Nutrients 2020; 12(4): 988.

58. Japelt RB and Jakobsen J, Vitamin D in plants: A review of occurrence, analysis, and biosynthesis. Front Plant Sci 2013; 4: 136.

59. Wang SC, Chen Y, Wang YC, et al., Tannic acid suppresses SARS-CoV-2 as a dual inhibitor of the viral main protease and the cellular TMPRSS2 protease. Am J Cancer Res 2020; 10(12): 4538-4546.

60. Chef's Pencil Staff. Top most popular countries and cities for vegans in 2020. Food Industry News 2020. Available at: https://www.chefspencil.com/top-most-popular-countries-and-cities-for-vegansin-2020/ [Accessed on 5 Jan 2021].

61. Clarys P, Deliens T, Huybrechts I, et al., Comparison of nutritional quality of the vegan, vegetarian, semi-vegetarian, pesco-vegetarian and omnivorous diet. Nutrients 2014; 6(3): 1318-32.

62. Willett W, Rockstrom J, Loken B, et al., Food in the Anthropocene: the EAT-Lancet Commission on healthy diets from sustainable food systems. Lancet 2019; 393(10170): 447-492.

63. Vernelli T. New study finds vegan meals cost $40 \%$ less than meat/fish. Veganuary 2020. Available at: https://veganuary.com/vegan-meals-cost-40-percent-less-than-meat-fish/ [Accessed on 5 Jan 2021]. 
64. International Labour Organization. Impact of the COVID-19 crisis on loss of jobs and hours among domestic workers. 2020. Available at: https://www.ilo.org/wcmsp5/groups/public/ [Accessed on 5 Jan 2021].

65. Acumen Research and Consulting. Vegan food market - Global industry analysis, market size, opportunities and forecast, 2019 - 2026. 2019. Available at: https://www.acumenresearchandconsulting.com/vegan-food-market [Accessed on 5 Jan 2021].

66. FAO-OIE-WHO. The FAO-OIE-WHO collaboration: sharing responsibilities and coordinating global activities to address health risks at the animal-human-ecosystems interfaces. A Tripartite Concept Note 2010. Available at: https://www.who.int/influenza/resources/documents/tripartite_concept_note_hanoi/en/ [Accessed on 5 Jan 2021].

67. World Bank. People, pathogens and our planet: the economics of one health. Washington, DC. World Bank Group 2012. Available at: https://openknowledge.worldbank.org/handle/10986/11892 [Accessed on 5 Jan 2021].

Author(s) shall retain the copyright of their work and grant the Journal/Publisher right for the first publication with the work simultaneously licensed under:

Creative Commons Attribution-NonCommercial 4.0 International (CC BY-NC 4.0). This license allows for the copying, distribution and transmission of the work, provided the correct attribution of the original creator is stated. Adaptation and remixing are also permitted. 